\title{
A POLÊMICA ENTRE LEOPOLDO ZEA E AUGUSTO SALAZAR BONDY SOBRE A EXISTÊNCIA DE UMA FILOSOFIA AMERICANA (1968-1969) ${ }^{1}$
}

\author{
Eugênio Rezende de Carvalho*
}

Resumo: Este artigo analisa o contexto e os argumentos do debate intelectual, travado em 1968-69, entre o filósofo mexicano Leopoldo Zea (1911-2004) e o peruano Augusto Salazar Bondy (1925-1974), cuja polêmica central, qual seja, a existência de uma filosofia latino-americana, tem suas raízes na tese lançada em meados do século XIX pelo pensador argentino Juan Bautista Alberdi (1810-1884).

Palavras-chave: Leopoldo Zea; Augusto Salazar Bondy; Filosofia latino-americana; Pensamento latino-americano; Juan Bautista Alberdi.

Abstract: This article analyzes the context and the arguments of the intellectual debate, held in 1968-69, between the Mexican philosopher Leopoldo Zea (1911-2004) and the Peruvian philosopher Augusto Salazar Bondy (1925-1974), whose central problem, the existence of a Latin American philosophy, has its roots in Argentine thinker Juan Bautista Alberdi's (1810-1884) theory.

Keywords: Leopoldo Zea; Augusto Salazar Bondy; Latin American Philosophy; Latin American Thought; Juan Bautista Alberdi.

*Doutor em História Social e das Ideias pela Universidade de Brasília (UnB), com estágio doutoral na Universidade Complutense de Madri e pósdoutorados em História pela Universidade de São Paulo (USP) e Universidade de Brasília (UnB). Atualmente é professor Associado da Universidade Federal de Goiás.E-mail:eugeniodecarvalho@gmail.com

${ }^{1}$ Texto publicado originalmente nos Anais do 9o Encontro Internacional da ANPHLAC - Associação Nacional de Pesquisadores em História das Américas. Goiânia: Universidade Federal de Goiás, 26 a 29 de julho de 2010. Disponível em: http://anphlac.org/upload/anais/encontro9/eugenio_carvalho. pdf 
$|182|$

A polêmica entre Leopoldo Zea...

\title{
$O$ contexto intelectual de emergência da polêmica
}

Em meados do século XIX, foi decisiva a polêmica levantada pelo pensador argentino Juan Bautista Alberdi (1810-1884) sobre a existência de uma filosofia americana. No ensaio intitulado Ideas para un curso de filosofía contemporánea, lido no Colégio de Humanidades de Montevidéu, em 1842, Alberdi declarou que a filosofia seria única em seus elementos fundamentais, como a humanidade, mas diversa em suas aplicações nacionais e temporais. (ALBERDI, 1993, pp.149-150). Segundo ele,

\begin{abstract}
Não há, pois, uma filosofia universal, porque não há uma solução universal para as questões de fundo que a constituem. Cada país, cada época, cada filósofo teve sua filosofia peculiar, que se difundiu mais ou menos, que durou mais ou menos, porque cada país, cada época e cada escola deram soluções distintas aos problemas do espírito humano. (ALBERDI, 1993, p. 145$)^{2}$
\end{abstract}

Segundo tal perspectiva, para o pensador argentino, uma filosofia contemporânea seria aquela que resolvesse os problemas que importam no seu momento. E assim como havia uma filosofia oriental, uma grega, uma romana, uma alemã, uma inglesa e uma francesa, era necessário que houvesse também uma filosofia americana, para resolver o problema dos destinos americanos (ALBERDI, 1993, p. 146, 149). Dessa forma, Alberdi propõe que se tome da filosofia chamada universal tão somente aquelas doutrinas, correntes e aspectos que melhor convenham à solução da problemática americana.

Posteriormente, a tese de Alberdi foi continuamente retomada por vários intelectuais e filósofos latino-americanos, embora, muitas vezes, para ser contestada. Num artigo publicado

\footnotetext{
${ }^{2}$ Todas as citações escritas originalmente em espanhol foram traduzidas ao
} português pelo autor deste artigo. 
em 1925 - com o sugestivo título Existe um pensamento hispanoamericano? - o filósofo, sociólogo e crítico literário peruano José Carlos Mariátegui (1895-1930) considerou ser evidente a existência de um pensamento francês, alemão etc. na cultura do Ocidente, muito embora não se pudesse dizer o mesmo em relação ao pensamento hispano-americano. Para ele

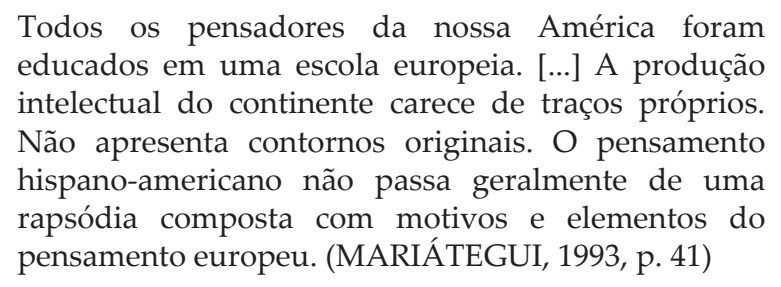

Em um ensaio de seu clássico Indología, livro de 1927, o filósofo mexicano José Vasconcelos (1881-1959) vai ainda mais longe ao proclamar abertamente a não existência de uma filosofia ibero-americana, ao ressaltar que

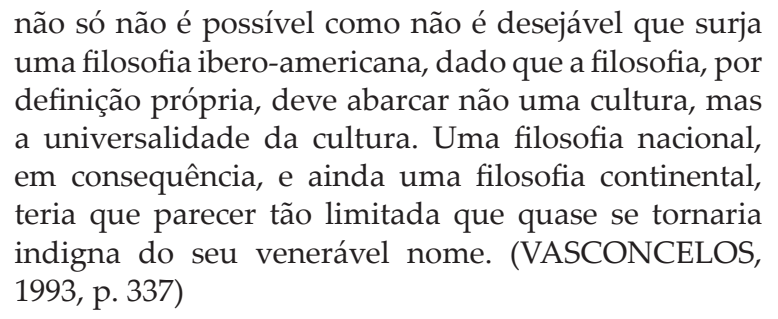

Alguns anos mais tarde, por sua vez, o filósofo espanhol exilado no México no final da década de 1930, José Gaos (19001969) - que viria a ser o grande mestre de Leopoldo Zea - volta a recolocar o problema da possibilidade de uma filosofia que pudesse ser chamada de americana, agora numa perspectiva mais otimista. Em um artigo de 1942, a partir de um paralelo com o contexto espanhol, ele afirmou que

Se espanhóis, mexicanos ou argentinos fazem um 
$|184|$

A polêmica entre Leopoldo Zea...

mínimo de filosofia, haverá pura e simplesmente filosofia espanhola, mexicana, argentina, americana. [...] A questão não está, pois, em se fazer filosofia espanhola ou americana, mas em espanhóis ou americanos fazerem filosofia. O que é preciso se preocupar não é, enfim, com o espanhol ou o americano, mas com o filosófico da filosofia espanhola ou americana. (GAOS, 1993, p. 482)

Mas a polêmica ganhará maior vigor a partir das décadas de 1940 e 1950, no contexto da Segunda Guerra Mundial, por meio dos representantes e teóricos do chamado movimento latinoamericano de história das ideias ${ }^{3}$, particularmente pelo filósofo mexicano Leopoldo Zea, para quem tal preocupação de Alberdi teria surgido "da busca de soluções para os problemas desta região da terra a partir de soluções dadas a problemas semelhantes pelo filosofar europeu e ocidental". (ZEA, 2000, p. 39) Segundo o filósofo argentino-mexicano Horacio Cerutti Guldberg, teria surgido nesse momento uma tradição de pensamento na América Latina que se autoproclamaria continuadora da tradição do historicismo romântico, iniciada principalmente por Alberdi:

À primeira vista, e de modo talvez superficial, pareceu constituir-se no correlato do processo de substituição de importações no nível da expressão máxima da cultura, o momento da autoconsciência: a filosofia. (CERUTTI GULDBERG, 1997, p. 184)

Em outras palavras, tratava-se da tendência de opor o caráter importado ao caráter autóctone do pensamento e da produção intelectual latino-americana, buscando, para tal, especificidades, nacionais ou latino-americanas, em relação ao pensamento europeu. ${ }^{4}$ Muito embora algumas vozes, como

\footnotetext{
${ }^{3}$ Para uma visão panorâmica acerca da história desse movimento intelectual, ver Carvalho (2009).

${ }^{4}$ Cf. Strozzi (1999, p. 8).
} 
a do filósofo peruano Francisco Miró de Quesada (1918-?), tenham contestado a crença recorrente de que o impulso rumo à autenticidade cultural se expressaria no desejo de realizar criações distintas das europeias. Para esse autor, tal impulso se manifestaria, ao contrário, na necessidade de uma experimentação radical das criações europeias, na tomada de consciência de que os produtos culturais ocidentais eram, ao mesmo tempo, importações e criações latino-americanas. (MIRÓ QUESADA, 1993, p. 140) ${ }^{5}$

Refletindo o clima filosófico da época, os congressos de filosofia realizados na América nos meados do século XX ainda repercutiriam a questão colocada por Alberdi há mais de um século. Desde o III Congresso Interamericano de Filosofia realizado no México, em 1950 -, já se discutiam as relações entre a filosofia universal e a filosofia (latino-)americana, ressaltando a legitimidade desta e sua inserção naquela. Em Buenos Aires, em 1959, o IV Congresso Interamericano de Filosofia já havia decidido não recolocar em discussão o tema da existência de uma filosofia americana, tal como ocorrera nos eventos anteriores porque se colocaria em dúvida a própria capacidade dos americanos de se reunirem em um convívio autenticamente filosófico. A propósito, segundo Leopoldo Zea,

a insistente pergunta sobre a possibilidade ou existência de uma filosofia na América, concretamente na América Latina, põe em dúvida a humanidade de quem interroga, já que, se o homem se distingue de outros seres da natureza por sua razão, por sua

\footnotetext{
${ }^{5}$ A propósito, Miró Quesada (1993, p. 133) afirma ainda: “Ao mesmo tempo em que aumenta seu autoconhecimento, a América Latina vai tratando de passar de uma cultura excêntrica, cujo eixo encontra-se inclinado na direção da Europa, rumo a uma cultura concêntrica, centrada em si mesma. Essa mudança de centro não significa de modo algum a negação da cultura ocidental, mas tão somente o desejo agudo de conseguir uma genuína integração, expressão de uma vontade de deixar a periferia e de se submergir nas profundidades do espírito criador".
} 
$|186|$

A polêmica entre Leopoldo Zea...

capacidade de objetivar, conhecer e comunicar, duvidar dessa capacidade seria duvidar do ser em si, do homem desta região. (ZEA, 1993b, p.361)

Mais tarde, em 1989, falando aos participantes do I Congresso de Filosofia Latino-Americana, Zea (1993b, p. 361) destacou que aquele evento, pelo seu enfoque, parecia "pôr fim definitivo aos complexos que colocavam em dúvida a capacidade de se filosofar ou de se refletir a partir da região, tendo como base modelos que determinavam sua possibilidade". Zea deixava clara, assim, sua repulsa às dúvidas sobre a capacidade dos pensadores latinoamericanos para o exercício da filosofia.

Tal reação deve ser compreendida como indignação ao que Antonello Gerbi (1904-1976), historiador italiano das ideias, chamou de calúnia contra a América. Em seu clássico livro dos anos 60, O Novo Mundo: história de uma polêmica (1750-1900), Gerbi apresentara, de forma bastante erudita, as raízes e a trajetória da tese da inferioridade das Américas, no tocante à sua natureza e à sua gente. Para tal, baseava-se na polêmica iniciada em meados do século XVIII pelo naturalista francês Conde de Buffon (1707-1788) e pelo abade prussiano Corneille De Pauw (17391799). Gerbi investigara os inúmeros argumentos utilizados pelos contendores, carregados de preconceitos de ordem teológica, biológica, histórica, científica ou pseudocientífica. Na sua análise, destacara queimaturidade,impotência, inferioridadee degeneração eram os termos mais recorrentes que povoaram, durante séculos, as acaloradas descrições da realidade americana.

Em meados do século XX, inúmeros intelectuais latinoamericanos reagiram às descrições negativas da realidade e dos habitantes da América. E, por extensão, às relações que a tese da inferioridade - e suas variantes e atualizações - guardaria com a já formação de uma consciência que valorizava a autorreflexão sobre a sua própria produção filosófica. Muitos se propuseram inclusive, 
consciente e expressamente, a dar continuidade à obra de Gerbi. ${ }^{6}$ É o caso do filósofo argentino Arturo Andrés Roig (1984, p. XVII), que, ao destacar a importância da obra de Gerbi para a história das ideias latino-americanas, reconheceu que aquele autor "a deixara generosamente aberta a nós". O propósito de Roig, Zea e de todo o seu grupo era, acima de tudo, superar o complexo de inferioridade, impotência, incapacidade e inumanidade que havia sido forjado durante séculos e ainda se mantinha de certa forma vigente, em pleno século $X X$, nos meios intelectuais latino-americanos. A propósito, Zea (2000, p. 26) escreveu:

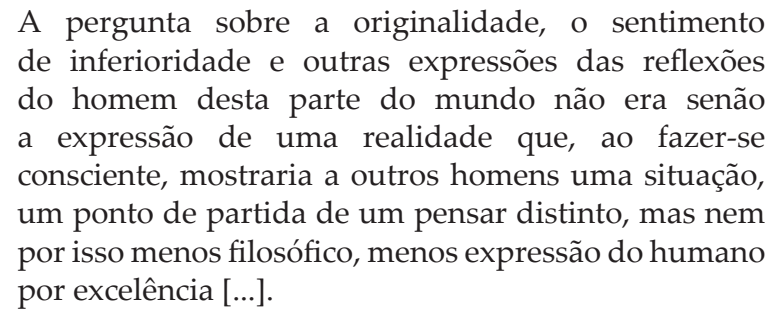

Assim, a indignação diante de tal complexo de inferioridade e o empenho em superá-lo por meio do reconhecimento da capacidade de um pensamento latino-americano autóctone, distinto e original, marcaram o contexto intelectual de emergência da polêmica objeto deste estudo. Vivia-se um momento em que a reflexão filosófica na América Latina tendia a voltar-se criticamente para si mesma, num autoquestionamento. Segundo Villoro (1993, p. 183), "em nossos países, a filosofia parece ter todos os traços da inautenticidade: falta de originalidade, superficialidade, carência de continuidade e, sobretudo, dependência imitativa da produção filosófica de outros países". Ainda conforme Villoro, adquirir

\footnotetext{
${ }^{6}$ Como Gerbi (1996) deixou inacabada a sua obra sobre a trajetória da tese da inferioridade das Américas, já que limitou sua análise ao ano de 1900, ele mesmo reconheceu que novos personagens e termos poderiam ser acrescentados na polêmica iniciada no século XVIII.
} 
| 188 |

A polêmica entre Leopoldo Zea...

consciência de tal situação e propor vias para superá-la foi a grande obra de vários intelectuais e filósofos latino-americanos.

Obviamente, debater a existência de uma filosofia americana ou a capacidade dos americanos para o seu exercício passava pela polêmica entre o particular e o universal em filosofia e, ainda, pela própria definição de filosofia. Em 1983, no seu discurso no encerramento do XVII Congresso Mundial de Filosofia, em Montreal, Canadá, Zea relembrou, retomando a polêmica levantada por Alberdi, como aquele evento reafirmara a inexistência de uma filosofia universal, ao proclamar "filosofias concretas que se universalizam à medida que são compreendidas por outros e que compreendem estes outros". E concluiu afirmando que a filosofia não expressa mais do que um modo limitado de compreender o mundo e de resolver seus problemas, não podendo, pois, restringir-se apenas a uma determinada forma de expressão humana em detrimento de outras (ZEA, 1993b, pp. 362, 379).

Ao criticar o caráter universalista abstrato assumido pela filosofia ocidental de matriz europeia, Zea procurava legitimar a filosofia latino-americana enquanto tal. Segundo ele, estudar a obra dos pensadores latino-americanos e investigar como eles tentaram captar a sua própria realidade social e histórica, para solucionar seus problemas concretos, já era fazer filosofia.?

Em suma, podemos afirmar que o debate sobre a autenticidade e originalidade da reflexão filosófica americana e latino-americana, de remotas origens, ganharia um novo impulso com a polêmica travada em 1968-1969 entre Zea e o filósofo peruano Augusto Salazar Bondy (1925-1974). Tal polêmica emergiu num contexto intelectual marcado por um acalorado debate filosófico. Sob a

\footnotetext{
7 É por essa peculiar concepção de filosofia que, para Zea - assim como para os principais integrantes do movimento latino-americano de história das ideias que ele liderou - a história dessa filosofia (latino-americana) era compreendida como história das ideias, e não como a tradicional e acadêmica história da filosofia (Cf. ROIG, 1994).
} 
influência do historicismo ${ }^{8}$, o impulso alcançado pelos estudos filosóficos na América Latina nesse período esteve vinculado à consolidação de uma consciência filosófica latino-americana que valorizou a reflexão sobre a sua própria produção intelectual em relação com as matrizes do pensamento filosófico europeu. Tal consciência filosófica esteve, por sua vez, acompanhada de um modo peculiar de entender a filosofia, como reflexão sobre os problemas concretos do contexto específico de quem a produz, em contraposição à concepção universalista abstrata preponderante na matriz filosófica europeia.

Partindo de uma peculiar definição de filosofia, setores importantes da intelectualidade latino-americana, em particular aqueles vinculados ao movimento latino-americano de história das ideias, passaram a defender não apenas a simples existência, mas também o caráter original de uma filosofia latino-americana, forjando uma consciência filosófica apoiada na elevação da autoestima e repelindo qualquer tese de inferioridade. Considerando a existência dessa filosofia latino-americana, ela poderia então ser historiada, e o objeto de tal história consistiria nas ideias expressas pelos pensadores - no caso, latino-americanos -, no processo de reflexão sobre a sua própria realidade social e histórica, com o propósito de apreendê-la e de dar solução aos seus problemas concretos.

\footnotetext{
${ }^{8}$ Há que se considerar aqui a forte presença, nesses meios intelectuais, do historicismo nas vertentes filosóficas do espanhol Ortega y Gasset e do alemão Wilhelm Dilthey. Um balanço importante dessas influências pode ser encontrado em vários textos de Leopoldo Zea, para quem a filosofia europeia se converteu em um dispositivo a serviço da tomada de consciência da realidade americana, na medida em que o filósofo e o historiador fizeram dessa filosofia um instrumento de busca de sua realidade. Foi o caso da filosofia alemã, ou da influência de Ortega y Gasset, que estimularam esses primeiros trabalhos de reflexão a partir da década de 1920 (ZEA, 1991).
} 
|190|

A polêmica entre Leopoldo Zea...

\section{A polêmica entre Zea e Salazar Bondy}

Conforme vimos, desde meados do século XIX, a tese de Juan Bautista Alberdi já havia inaugurado o debate sobre a existência de uma filosofia americana. Nas primeiras décadas do século XX e, com maior vigor, a partir das décadas de 1940 e 1950, tal polêmica continuava repercutindo, atravessando diferentes fases e intensidades, em sucessivas gerações de pensadores americanos. Mas essa polêmica sobre a autenticidade e originalidade do pensamento filosófico americano e latino-americano ganharia um novo fôlego em 1968, com a publicação do livro de Augusto Salazar Bondy, que levava o instigante título ¿Existe una filosofía de nuestra América? ${ }^{9}$ Nele o filósofo peruano lançava algumas teses provocadoras a respeito do tema, as quais Zea procuraria contestar em seu livro, publicado no ano seguinte, em 1969, sob o título $L a$ filosofía americana como filosofía sin más. ${ }^{10}$

Em seu livro, Salazar Bondy (2004) partiu da descrição de alguns expoentes do pensamento hispano-americano com o propósito de identificar a expressão de uma filosofia original, genuína ou peculiar, conforme a definição que deu a esses termos. Em seguida, prescreveu algumas condições para assegurar a autenticidade de tal filosofia. Em cumprimento aos seus objetivos, ele analisou as posições contrárias e favoráveis à afirmação de que existe uma filosofia genuinamente americana. Entre as posições favoráveis, Salazar Bondy situou a obra do filósofo espanhol José Gaos, ${ }^{11}$ cuja posição a respeito do tema seria reforçada

\footnotetext{
${ }^{9}$ Utilizou-se como fonte neste estudo a 16o edição desse livro, publicada pela editora mexicana Siglo XXI, em 2004.

${ }^{10}$ No âmbito deste estudo, utilizou-se como fonte a versão em língua portuguesa desse livro, publicada no Brasil em 1993, pela editora Pensieri.

${ }^{11}$ Salazar Bondy resumiu os pressupostos filosóficos de Gaos a respeito desse tema nos seguintes pontos: 1) há uma filosofia ou um pensamento filosófico mexicano e, por extensão, hispano-americano; 2) essa filosofia é distinta da
} 
por Zea e pela maioria dos estudiosos da história das ideias na América Latina, influenciados principalmente pelas correntes de pensamento filosófico de cunho historicista e culturalista. ${ }^{12}$

Um dos pontos basilares que fundamentam toda a argumentação de Salazar Bondy na polêmica sobre a existência de uma filosofia hispano-americana tem a ver com as delimitações estabelecidas por ele no âmbito terminológico-conceitual. Mais especificamente, com a forma com que maneja e concebe os termos originalidade, autenticidade, genuinidade e peculiaridade, no campo da filosofia.

Salazar Bondy emprega o termo originalidade para se referir à qualidade inerente a algo que é fruto de uma criação inovadora, inédita, em contraposição à qualidade atribuída a algo decorrente de uma mera repetição, imitação ou cópia. ${ }^{13}$ Já os termos genuinidade e autenticidade, ${ }^{14}$ que o autor emprega como sinônimos, significariam, em linhas gerais, a qualidade de algo legítimo, verdadeiro, fidedigno, puro, insuspeito, correto ou preciso, em oposição a algo falso, equivocado, ambíguo, impreciso, desvirtuado, defeituoso ou

filosofia dos países ocidentais; 3) tal filosofia constitui um aporte genuíno e original ao pensamento mundial.

${ }^{12}$ Salazar Bondy cita explicitamente o boliviano Guillermo Francovich, os panamenhos Diego Dominguez Caballero e Ricaurte Soler, o mexicano Abelardo Villegas e o uruguaio Arturo Ardao - este último que tanto já havia ressaltado a função do historicismo na tomada de consciência da cultura e do sentido do pensamento filosófico latino-americano.

${ }^{13}$ No contexto e na relação com a filosofia, Salazar Bondy (2004, p. 72) emprega o termo originalidade para significar "o aporte de ideias e enfoques novos, em maior ou menor grau, relativo às realizações anteriores, mas suficientemente discerníveis como criações e não como repetições de conteúdos doutrinários". Nesse sentido, uma filosofia original seria identificável por construções conceituais inéditas de reconhecido valor.

${ }^{14} \mathrm{O}$ autor emprega esses termos para significar "um produto filosófico - tal como um produto cultural qualquer - que se dá como propriamente tal e não como falseado, equivocado ou desvirtuado" (SALAZAR BONDY, 2004, p. 72). 
|192 |

A polêmica entre Leopoldo Zea...

imperfeito. Por fim, o termo peculiaridade é empregado para referir-se à

presença de traços histórico-culturais diferenciais, que dão caráter distinto a um produto espiritual - neste caso filosófico; trata-se de um tom, digamos, local ou pessoal, que não implica inovações de conteúdo substantivo. (SALAZAR BONDY, 2004, p. 72)

Nesse sentido, as diferentes pessoas, povos, classes e épocas teriam sempre peculiaridades que estariam refletidas em suas respectivas filosofias. De uma forma geral, o autor reconhece que, embora distintos, esses termos ocorrem interconectados. Assim, segundo tal perspectiva, "um pensamento que não é genuíno dificilmente pode ter originalidade, mas um pensamento que não é original pode ser peculiar" (SALAZAR BONDY, 2004, pp. 72-73). Por outro lado, a originalidade garante de algum modo não apenas a peculiaridade de uma filosofia, mesmo que nela predomine a imitação, mas também a sua autenticidade.

Para Salazar Bondy, a peculiaridade seria o traço mais frequente nos produtos ideológicos, em razão dos condicionamentos históricos que marcam as sociedades humanas. $\mathrm{E}$, ao contrário, ter acesso à genuinidade e à originalidade do pensamento seria algo difícil e incomum. Aplicando essas distinções ao caso específico da filosofia hispano-americana, o autor reconhece que foram formuladas teses tanto sobre a peculiaridade quanto sobre a autenticidade e a originalidade desse pensamento, que defenderam ora a existência de apenas uma dessas qualidades, ora apenas duas delas, ou ainda as três somadas.

Após descrever um quadro minucioso das diversas posições contrárias e favoráveis à existência de uma filosofia hispanoamericana, Salazar Bondy, finalmente, formulou a sua própria resposta à pergunta que motivou e deu título ao seu livro. Tal resposta foi sintetizada em um conjunto de pontos, que vão do diagnóstico do problema à prescrição de sua solução. Eis a íntegra 
dos pontos que resumem as teses de Salazar Bondy:

I. Nossa filosofia, com suas peculiaridades próprias, não tem sido um pensamento genuíno e original, mas sim inautêntico e imitativo no fundamental;

II. A causa determinante desse fato é a existência de um defeito básico de nossa sociedade e de nossa cultura. Vivemos alienados pelo subdesenvolvimento conectado à dependência e à dominação a que estamos e sempre estivemos sujeitos;

III. Nossa vida alienada como nações e como comunidade hispano-americana produz um pensamento alienado que a expressa por sua negatividade. Nossa sociedade não pode produzir mais do que semelhante pensamento defectivo;

IV. Esse pensamento inautêntico, por ser alienado, é ainda alienante, uma vez que funciona geralmente como imagem encobridora de nossa realidade e fator coadjuvante no divórcio de nossas nações em relação ao seu próprio ser e suas justas metas históricas;

V. A constituição de um pensamento genuíno e seu normal desenvolvimento não poderão ser alcançados sem que se produza uma decisiva transformação da nossa sociedade, mediante o cancelamento do subdesenvolvimento e da dominação;

VI. Nossa filosofia genuína e original será o pensamento de uma sociedade autêntica e criadora, tanto mais valiosa quanto mais altos níveis de plenitude alcance a comunidade hispano-americana. Porém, pode começar a ser autêntica como pensamento da negação de nosso ser e da necessidade de mudança, como consciência da mutação inevitável de nossa história. Pela análise e crítica, pela confrontação dos valores vigentes em nosso mundo e pelo aprofundamento da própria condição, pode operar como um pensamento já não inteiramente defectivo, 
|194|

A polêmica entre Leopoldo Zea...

mas crescentemente criador e construtivo;

VII. Porém, como seguirá tomando de fora, talvez por muito tempo, conceitos e valores, deverá ser vigilante e desconfiada ao extremo, a fim de evitar - pela crítica e pela consulta da realidade - a recaída nos modos alienantes de reflexão;

VIII. As nações do Terceiro Mundo, como as hispano-americanas, têm de forjar sua própria filosofia em contraste com as concepções defendidas e assumidas pelos grandes blocos de poder atuais, fazendo-se desse modo presentes na história de nosso tempo e assegurando sua independência e sua sobrevivência. (SALAZAR BONDY, 2004, pp. 93-94)

$\mathrm{Na}$ verdade, sua resposta se apoia no postulado de que o pensamento filosófico na Hispano-América não tem sido genuíno nem original, mas inautêntico e imitativo. Para ele,

o certo é que os hispano-americanos estão claramente no caso deste existir inautêntico: vivemos desde um ser pretendido, temos a pretensão de ser algo distinto do que somos e do que poderíamos porventura ser; ou seja, vivemos alienados em relação à própria realidade que se oferece como uma instância defectiva, com carências múltiplas, sem integração e, portanto, sem vigor espiritual. (SALAZAR BONDY, 2004, p. 83)

Para Salazar Bondy, o problema da inautenticidade ${ }^{15}$ residiria, portanto, na alienação decorrente da condição histórica

\footnotetext{
${ }^{15}$ Trata-se de uma posição que se aproxima, de certa forma, de uma tradição historiográfica desenvolvida dentro e fora da América Latina que, em linhas gerais, segundo Cerutti Guldberg (1997, pp. 183-184), “tem negado a existência de uma reflexão filosófica específica ou característica da América Latina, partindo da postulação da mera repetição, cópia ou deformação, por parte dos latino-americanos, de conceitos produzidos na Europa ou nos Estados Unidos. Essa tradição tem enfatizado sempre o 'atraso' na recepção das 'influências' por parte dos latino-americanos e trabalhado com a noção (metáfora) historiográfica das oleadas."
} 
de subdesenvolvimento e dominação a que estavam sujeitas essas sociedades que, uma vez alienadas, produziam um pensamento igualmente alienado, imperfeito e, consequentemente, dissimulador de sua própria realidade. Uma vez diagnosticado o problema, Salazar Bondy prescreveu as condições para se desenvolver um pensamento genuíno e original na Hispano-América ${ }^{16}$ que dependeria do fim da condição de subdesenvolvimento e de dominação a que estavam submetidas essas sociedades. Porém, esse pensamento poderia gradualmente ir se transformando em autêntico, genuíno e original, proporcionalmente ao nível alcançado de consciência e de negação dessa condição, capaz de desencadear a sua superação.

Zea, por sua vez, ao rebater essas teses em seu livro La filosofía americana como filosofía sin más, de 1969, propõe-se a deslocar o foco da pergunta sobre a existência de uma filosofia latino-americana, colocando em questão a própria definição e função da filosofia, a partir das relações e diferenças entre a filosofia latino-americana e a filosofia ocidental. ${ }^{17}$ Apoiando-se em uma perspectiva

${ }^{16}$ Salazar Bondy (2004, p. 89), ao tratar das possibilidades da superação do problema que afetava a filosofia hispano-americana, considerou que ele estaria na dependência da "superação do subdesenvolvimento e da dominação, de tal maneira que se pode haver uma filosofia autêntica, ela há de ser fruto dessa mudança histórica transcendental. Mas não é preciso esperá-lo; não há por que ser somente um pensamento que sanciona e coroa os fatos consumados. Pode ganhar sua autenticidade como parte do movimento de superação de nossa negatividade histórica, assumindo-a e esforçando-se em cancelar suas raízes. A filosofia tem, pois, na Hispano-América, uma possibilidade de ser autêntica em meio à inautenticidade que a rodeia e a afeta: converter-se na consciência lúcida de nossa condição deprimida como povos e no pensamento capaz de desencadear e promover o processo superador dessa condição".

17 Essas questões, assim como as relativas à autenticidade e originalidade filosófica latino-americana, já se encontravam presentes na obra de Zea desde a década de 1940, em livros como Ensayos sobre filosofía en la historia, América como conciencia, La conciencia del hombre en la filosofía, La filosofía en México e Introducción a la filosofia, entre outros, sem contar sua presença em um grande número de artigos e capítulos. E continuarão sendo recorrentes em outros 
eminentemente historicista, que proclama a "originalidade, a individualidade, a irredutibilidade do espírito em função das circunstâncias de tempo e de lugar" (ARDAO apud ZEA, 1993a, p. 87), Zea formula sua posição filosófica a partir da crítica ao universalismo hegemônico e abstrato da filosofia ocidental, contrapondo a ela uma noção de filosofia como expressão de uma circunstância histórico-cultural concreta.

Não seria a partir do paradigma da filosofia ocidental, na forma como Zea a interpreta, que se deveria buscar, segundo ele, a resposta sobre a existência de uma tradição filosófica latinoamericana, pois, nesse caso, a resposta seria evidentemente negativa. Tal resposta deveria considerar outros aspectos ou funções da filosofia, ou seja, não apenas a função de refletir sobre questões metafísicas ou abstratas, lógicas ou metodológicas, mas fundamentalmente a de refletir sobre os problemas concretos de sua circunstância (sociais, políticos, culturais) e a de contribuir, assim, para a sua solução. Esta última seria, segundo Zea (1993a), a característica e a função básica que historicamente havia assumido a filosofia latino-americana. A conclusão, portanto, é a de que existia uma filosofia latino-americana, mas de caráter eminentemente instrumental, pragmático, engajado, comprometido com a sua própria realidade ou circunstância concreta.

Numa crítica indireta à posição de Salazar Bondy, Zea questiona se por originalidade deveria se entender apenas a "capacidade dos latino-americanos para criar sistemas filosóficos tal como fizeram os filósofos europeus" e afirma que ela não seria alcançada se

$$
\begin{aligned}
& \text { nosso empenho se direciona à criação de sistemas } \\
& \text { metafísicos que não sejam o resultado de uma } \\
& \text { necessidade vital, o respaldo ideológico de uma ação, } \\
& \text { tal como têm sido os sistemas da filosofia ocidental; } \\
& \text { ou ainda a assimilação de uma filosofia como técnica } \\
& \text { científica, se ela carece dos elementos quelhe permitam, } \\
& \text { como sucede no mundo ocidental, fazer da teoria uma }
\end{aligned}
$$

trabalhos posteriores, especialmente no livro Filosofía latinoamericana. 
práxis a seu serviço. (ZEA, 1993a, pp. 41, 78)

Contudo, de acordo com Zea, mesmo as filosofias provenientes de outras circunstâncias (como a europeia) poderiam resolver problemas de outra realidade (como a latino-americana), lançar luzes sobre eles, ainda que as soluções apresentadas não fossem necessariamente idênticas. Assim, as filosofias alheias poderiam ser emprestadas, tomadas como instrumentos para solucionar adequadamente os problemas próprios num processo de adaptação e assimilação.

Zea considera que a filosofia latino-americana teria passado, historicamente, de uma inautenticidade original a uma autenticidade da assimilação. Assimilar, para ele, ao contrário de meramente imitar, seria "tornar próprio aquilo que parece estranho, acomodá-lo ao que se é, sem pretender, pelo contrário, acomodar o próprio ser ao que lhe é estranho" (ZEA, 1993a, p. 39). Não se tratava simplesmente do direito de copiar, ${ }^{18}$ mas de tornar próprios certos valores que se apresentavam como universais e, como tais, ao alcance de todos os seres humanos. A partir de seus estudos e reflexões sobre o pensamento latino-americano, Zea passou a perceber aos poucos que

o que pareciam simples cópias malfeitas do filosofar por excelência vão se convertendo em expressões originais de um pensamento que tem adaptado o supostamente imitado à realidade que lhe apresenta problemas que urge resolver. (ZEA, 1988, p. 16)

Quando seus críticos contra-argumentavam que aquilo não era filosofia, Zea respondia categoricamente: "pior para a filosofia!". No fundo, o filósofo mexicano estava alertando

${ }^{18}$ Zea (1993a, p. 64) reconhecia: “Na própria ação de copiar, de decalcar, ocorre ainda que, sem pretender e talvez apesar de nós mesmos, algo de nosso modo de copiar, de nosso modo de decalcar, torna o original diferente do decalque". Mas tal diferença, enquanto assimilação, não significava para o autor uma deformação carente de autenticidade. 
| 198 |

A polêmica entre Leopoldo Zea...

para a necessidade de se reavaliarem, portanto, os conceitos de originalidade e autenticidade filosóficas aplicados na compreensão dos processos de importação de ideias na América Latina. Obviamente, sua perspectiva marcadamente historicista - apoiada no circunstancialismo orteguiano - fazia com que sua noção de peculiaridade de um pensamento (aplicada ao caso latinoamericano) - na medida em que se ligava aos aspectos históricoculturais de sua produção - fosse mais determinante e proeminente (quanto às possibilidades de alterar os sentidos de originalidade e autenticidade de uma filosofia) do que a perspectiva de Salazar Bondy. Para Zea, as interconexões entre tais conceitos seriam muito mais efetivas. Na medida em que a repetição, imitação ou cópia fossem empregadas como instrumentos de solução de problemas concretos (sociais, políticos, culturais) - perspectiva ausente em Salazar Bondy -, já não seria uma distorção, deformação ou cópia defeituosa da filosofia importada. Tratar-se-ia de uma adaptação ou assimilação - segundo a terminologia de Zea - que poderia resultar num pensamento diferente e inovador, portanto, autêntico e original.

Procurando assim demarcar suas diferenças em relação às posições de Salazar Bondy, Zea concluiu finalmente sua posição sobre a polêmica, reiterando que existia efetivamente uma filosofia latino-americana (da qual o próprio Salazar Bondy era exemplo), "independentemente mesmo da forma que ela tenha tomado ou da sua autenticidade ou inautenticidade" (ZEA, 1993a, p. 155). Independentemente dos desdobramentos desse debate, ${ }^{19}$

\footnotetext{
${ }^{19}$ Logo foram incorporados a esse debate novos atores como, por exemplo, o filósofo argentino Enrique Dussel (1932-). Defendendo-se da acusação por parte de Zea de que estaria partilhando das mesmas teses de Salazar Bondy, Dussel (1992, p. 212) argumentou que "não se pretende negar o passado de um pensamento latino-americano liberador. $\mathrm{O}$ que negamos com Salazar Bondy é a existência de uma filosofia crítica latino-americana na 'etapa de normalidade filosófica', e que tenha podido enquanto filosofia latino-americana se autoafirmar e ser reconhecida como expressão de filosofia universal, a que se pratica nos programas centrais dos estudos filosóficos e não na especialidade de estudos latino-americanos, ou como cátedra específica". E, mais adiante,
} 
os pontos de divergência entre os dois autores são, na verdade, bem menores do que aparentam à primeira vista. ${ }^{20}$ Ao procurar contestar a tese de Salazar Bondy sobre a inautenticidade da filosofia latino-americana, Zea procurou ressaltar, em última instância, a importância das relações pragmáticas mantidas entre as filosofias importadas e a realidade latino-americana, dentro dos processos de sua adaptação e assimilação a essa realidade. Segundo o mexicano, esses processos (ainda que vistos como distorções de filosofias alheias) expressavam muito mais a realidade dos seus sujeitos latino-americanos do que a realidade de onde a filosofia adaptada se originara. Ou seja, na adoção realizada, o sujeito latino-americano expressava a si mesmo e a sua realidade de forma autêntica.

Nessa mesma linha, Fornet-Betancourt (1993) argumenta que a história das ideias (filosóficas) na Hispano-América nasce com o desafio de esclarecer a relação existente entre as ideias adaptadas e a realidade histórico-cultural a que foram adaptadas, ou, ainda, mais do que descrever o assimilado, perscrutar a lógica interna que regula a assimilação de ideias europeias e sua vinculação histórica. Segundo o autor, Zea procurava buscar, por meio de sua história das ideias, exatamente a lógica normativa da assimilação, sendo justamente a tomada de consciência de tal lógica a "condição possibilitadora de uma maneira de expressão espiritual propriamente hispano-americana" (FORNET-

Dussel esclarece que "é com respeito a essa 'filosofia' pretensamente universal (concretamente norte-americana-europeia) da qual estamos excluídos [...]. Como 'excluídos' dela, devemos 'interpretá-la' para que nosso discurso filosófico próprio seja 'reconhecido'”' (DUSSEL, 1992, p. 214).

20 A propósito, Fornet-Betancourt (1993, p. 50) escreve: “No fundo, a divergência entre ambos os pensadores se apoia, a nosso ver, no que para um - Zea - é já autêntica filosofia americana, para o outro - Salazar Bondy - constitui, entretanto, o caminho ou o exercício preparatório pelo qual se vêm criando as condições da realização de um pensamento filosófico autêntico". Segundo esse autor, ambos compartilhavam, no fundo, o projeto comum de uma filosofia comprometida com o processo de libertação latinoamericana. 
|200|

A polêmica entre Leopoldo Zea...

BETANCOURT, 1993, p. 20). Dessa forma, ainda de acordo com esse autor, é precisamente no sentido (ou espírito) que motiva essa lógica da assimilação que residiria a expressão própria desse pensamento. ${ }^{21}$ É nesse ponto que reside o mais importante significado da polêmica entre Zea e Bondy: o de instigar uma já preexistente preocupação de Zea em dar ainda mais relevo, como objeto de investigação, à lógica interna dos processos histórico-culturais latino-americanos de adaptação e assimilação das ideias oriundas da matriz filosófica europeia ou ocidental, redefinindo e flexibilizando os próprios conceitos de originalidade e autenticidade filosóficas.

\section{Bibliografia}

ALBERDI, Juan Bautista. "Ideas para un curso de filosofía contemporánea". In: ZEA, Leopoldo (comp.). Fuentes de la cultura latinoamericana. Vol. I. México: Fondo de Cultura Económica, 1993. pp. 145-151. [Escrito originalmente em 1842] Disponível em: <http://www.hacer.org/pdf/Ideas.pdf>. Acesso em: 31/07/2006.

CARVALHO, Eugênio Rezende de. Pensadores da América Latina: o movimento latino-americano de história das ideias. Goiânia: Editora UFG, 2009.

CERUTTI GULDBERG, Horacio. Hacia una metodología de la historia de las ideas (filosóficas) en América Latina. 2a ed. México: Centro Coordinador y Difusor de Estudios Latinoamericanos UNAM, 1997.

\footnotetext{
${ }^{21}$ E, assim, conclui Fornet-Betancourt (1993, p. 22): “O estudo da história das ideias filosóficas na Hispano-América descobre o sentido da realidade americana enquanto realidade dependente; ao mesmo tempo, o processo de assimilação de ideias europeias, como um processo animado por um espírito que assimila ideias estranhas, justamente para modificar essa situação, traz assim as coordenadas ao interior das quais tem de se consumar o projeto de uma filosofia própria e autêntica do homem americano".
} 
DUSSEL, Enrique. El proyecto de una filosofía de la historia latinoamericana. Cuadernos Americanos: Nueva Época, no 35, vol. 5, 1992, pp. 203-218.

FORNET-BETANCOURT, Raúl. Problemas atuais da filosofia na Hispano-América. São Leopoldo, RS: Editora Unisinos, 1993.

GAOS, José. ¿Filosofía americana? In: ZEA, Leopoldo (comp.). Fuentes de la cultura latinoamericana. Vol. I. México: Fondo de Cultura Económica, 1993. pp. 479-483. [Publicado originalmente em 1942, em Cima, no 5.]

GERBI, Antonello. O novo mundo: história de uma polêmica (17501900). São Paulo: Companhia das Letras, 1996.

MARIÁTEGUI, José Carlos. ¿Existe un pensamiento hispanoamericano? In: ZEA, Leopoldo (comp.). Fuentes de la cultura latinoamericana. Vol. II. México: Fondo de Cultura Económica, 1993. pp. 37-45 [Publicado originalmente em 1925, em Mundial, Lima, e em El Argentino, La Plata.]

ROIG, Arturo Andrés. La "historia de las ideas" cinco lustros después: estudio introductorio de la edición facsimilar de los números 1 y 2. Revista Historia de las Ideas, Quito, Banco Central del Ecuador, 1984. (Colección de Revistas Ecuatorianas). [Original: 1959, Revista Historia de las Ideas, n. 1, pp. I-XLII]

. El pensamiento latinoamericano y su aventura. 2 Tomos. Buenos Aires: Centro Editor de América Latina, 1994.

SALAZAR BONDY, Augusto. ¿Existe una filosofía en nuestra América? 16a. ed. México: Siglo XXI, 2004. [Edição original de 1968]

STROZZI, Susana. El discurso del método y el método de los discursos en la historia intelectual de América Latina. In: CANCINO TRONCOSO, Hugo et al. (eds.). Nuevas perspectivas teóricas y metodológicas de la historia intelectual de América Latina. Madrid: Iberoamericana; Frankfurt am Main: Vervuer, 1999. pp. 1-14. 
VASCONCELOS, José. El pensamiento iberoamericano. In: ZEA, Leopoldo (comp.). Fuentes de la cultura latinoamericana. Vol. I. México: Fondo de Cultura Económica, 1993. pp. 337-343. [Publicado originalmente em 1927, em Indología.]

VILLORO, Luis. Sobre el problema de la filosofía latino-americana. In: ZEA, Leopoldo. Filosofar a la altura del hombre: discrepar para comprender. Cuadernos Americanos, n. 4. México: Universidad Autónoma de México, 1993. pp. 183-201.

ZEA, Leopoldo. Autopercepción intelectual de un proceso histórico: autobiografía intelectual - bibliografía de y sobre Leopoldo Zea. Anthropos: Revista de Documentación Científica de la Cultura, n. 89, 1988, pp. 11-33.

. La filosofía como compromiso de liberación - Antología. Caracas: Biblioteca Ayacucho, 1991.

. 1993a. A filosofia americana como filosofia. São Paulo: Pensieri.

.1993b. Filosofar a la altura del hombre: discrepar para comprender. Cuadernos Americanos, n. 4. México: Universidad Nacional Autónoma de México.

José Gaos. Cuadernos Americanos. Nueva Época, vol. 1, n. 79, 2000, pp. 13-57. 